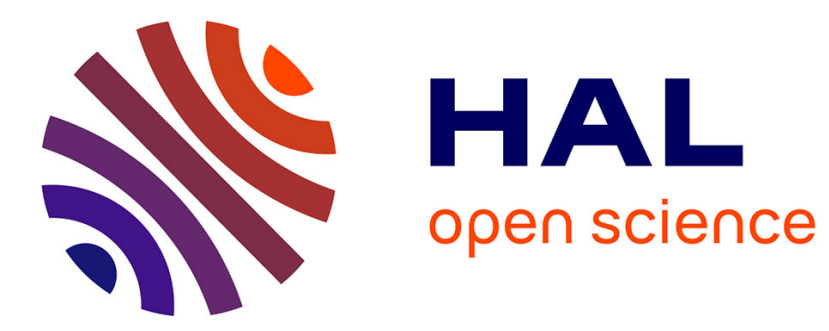

\title{
Modes of response of an offshore wind turbine with directional wind and waves
}

\author{
Maxime Philippe, Aurélien Babarit, Pierre Ferrant
}

\section{To cite this version:}

Maxime Philippe, Aurélien Babarit, Pierre Ferrant. Modes of response of an offshore wind turbine with directional wind and waves. Renewable Energy, 2013, 49, pp.151-155. 10.1016/j.renene.2012.01.042 . hal-01145150

\author{
HAL Id: hal-01145150 \\ https://hal.science/hal-01145150
}

Submitted on 2 Jun 2019

HAL is a multi-disciplinary open access archive for the deposit and dissemination of scientific research documents, whether they are published or not. The documents may come from teaching and research institutions in France or abroad, or from public or private research centers.
L'archive ouverte pluridisciplinaire HAL, est destinée au dépôt et à la diffusion de documents scientifiques de niveau recherche, publiés ou non, émanant des établissements d'enseignement et de recherche français ou étrangers, des laboratoires publics ou privés. 


\title{
Modes of response of an offshore wind turbine with directional wind and waves
}

\author{
M. Philippe*, A. Babarit, P. Ferrant \\ Laboratoire de Mécanique des Fluides, Ecole Centrale Nantes, Nantes, France
}

\begin{abstract}
A coupled dynamic analysis of a floating wind turbine system has been performed to investigate effect of wave direction relative to wind on the system. Hydrodynamic loads are calculated by linear frequency domain approach and aerodynamic effect is taken into account by increasing hydrodynamic damping and restoring matrices with aerodynamic damping and gyroscopic stiffness.

A modal analysis of the system was made to explain the calculated motions. It brings out the natural frequencies, natural modes and modal damping coefficients of the system. Excitation of natural modes, by waves explains the motion observed in the response amplitude operators, and the effect of wave direction relative to wind. This modal analysis helps to better understand the behaviour of floating wind turbine systems.
\end{abstract}

\section{Introduction}

Offshore wind resource is much vaster than onshore because wind blows more strongly and consistently offshore. Furthermore, the use of unoccupied marine areas reduces visual and noise annoyance; and turbines are able to have larger dimensions and therefore more power. Floating wind turbines are gaining attention for their ability to capture the wind resource over deep water areas where monopile-supported platforms become uneconomical.

In these floating systems, nacelle oscillating motions have to be minimized in order to limit material fatigue. Coupling between wave induced motion and turbine motion is intended to be significant, and have to be taken into account during design analysis.

Some studies have already been done to evaluate numerically the behaviour of such floating wind turbine systems. Some of theme use linear frequency domain approach to resolve hydrodynamic loads on the platform. Wind turbine influence on the platform is taken into account by increasing loads on the platform with linear aerodynamic damping and linear gyroscopic stiffness $[1,2]$.

This study uses the same approach, for the calculation of system movements as in Refs. [1,2], with some significant improvements. The effect of the wave direction relative to wind on the system motion is studied. A modal analysis of the system completes this analysis and gives information on system natural motion and on the coupling between system degrees of freedom. This paper is more focused on the presentation of the results. The methodology, briefly presented here, is explained in more details in Ref. [3].

\footnotetext{
* Corresponding author.

E-mail address: maxime.philippe@ec-nantes.fr (M. Philippe).
}

\section{Methodology}

\subsection{Model properties}

The system is assumed to undergo rigid body motion. System motions are described in the coordinate system represented on Fig. 3. The coordinate system origin is vertically aligned with the platform gravity centre, and is placed in calm surface water line plan. This origin is the reference for system motions, which are described with classical degrees of freedom (DOFs): surge (1), sway (2), heave (3) for the translations and roll (4), pitch (5), yaw (6) for the rotations (Fig. 1).

In this study, wind direction is chosen to be aligned with positive $x$ axis direction. $\beta$ is the angle between wave direction and wind direction. $\beta=0$ means that waves are coming from negative $x$. All simulations are realized with an $11.2 \mathrm{~m} \mathrm{~s}^{-1}$ wind speed. This is the wind speed for which the studied turbine reaches his rated power. For this wind speed the rotor thrust reaches his maximum value.

The wind turbine used in this study is the model known as "NREL offshore 5-MW baseline wind turbine" [4]. Main properties of this turbine are given in Table 2; all properties are available in Ref. [4].

The wind turbine is mounted on the platform known as "MIT/ NREL Shallow Drafted Barge (SDB)" [1]. It is a cylindrical barge. The stability of this design is based on the moment of inertia of the floating surface. The platform is placed in a $200 \mathrm{~m}$ water depth.

Design of this barge has been thought to be stable without mooring. Accordingly, the mooring lines provide station keeping functions only. Moorings loads on the platform are taken into 


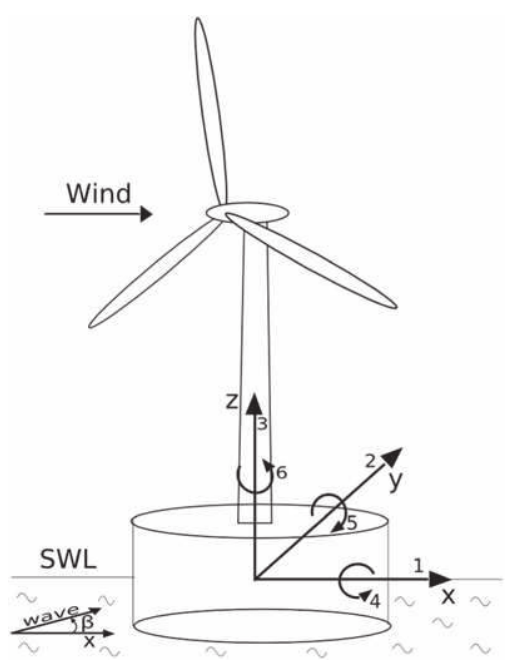

Fig. 1. Coordinate system and modes of motion.

account with a stiffness matrix. The only non-zero terms in this matrix are surge-surge and sway-sway stiffness. Table 1 summarizes the properties of the platform; the concept is explained in details in Refs. [1,2].

Design of "MIT NREL SDB", large floating surface, is in the domain of validity of the hydrodynamic modelling of this study. In fact, for linear frequency domain hydrodynamic theory, floater dimensions have to be larger than wave amplitude.

\subsection{Overall study approach}

This study is composed of two parts, a dynamic analysis and a modal analysis. The dynamic analysis part resolves the Response Amplitude Operators (RAOs) of the floating wind turbine system under wave loads. This dynamic analysis is based on the methodology described in Ref. [2], but takes into account significant differences, especially for the wind turbine linearization [3]. The modal analysis part completes the dynamic analysis. It provides access to natural frequencies, natural modes and modal damping coefficients of the floating wind turbine system. This information helps to understand the forced motions of the structure, and highlights the coupling between the DOFs of the system. Links between the different steps of this study are represented in Fig. 2.

The total external load on the system: platform, mooring, wind turbine comes from wind and waves. In this study we consider the system as a rigid body, and we calculate the motions of the platform. Loads acting on the platform are: fluid reaction $F_{\text {hydro, }}$ mooring loads $F_{\mathrm{a}}$ and loads transmitted from the turbine to the platform $F_{\text {aero. }}$. System equation of motions is:

$M_{\mathrm{p}} \ddot{q}=F_{\text {aero }}+F_{\text {ancrage }}+F_{\text {hydro }}$

with $M_{\mathrm{p}}$ the platform inertia matrix, and $q$ the vector of degrees of freedom.

Table 1

Summary of platform properties.

\begin{tabular}{ll}
\hline Diameter & $36 \mathrm{~m}$ \\
Draft, Freeboard & $5 \mathrm{~m}, 4.5 \mathrm{~m}$ \\
Mass, ballast height & $4153 \cdot 10^{3} \mathrm{~kg}, 1.595 \mathrm{~m}$ \\
Total mass & $4519 \cdot 10^{3} \mathrm{~kg}$ \\
CM location & $-3.9 \mathrm{~m}$ \\
Roll, pitch inertia about CM & $3.9 \cdot 10^{8} \mathrm{~kg} \mathrm{~m}^{-2}$ \\
Yaw inertia about MC & $7.5 \cdot 10^{8} \mathrm{~kg} \mathrm{~m}^{-2}$ \\
\hline
\end{tabular}

Table 2

Summary of turbine properties.

\begin{tabular}{ll} 
Turbine rate & $5 \mathrm{MW}$ \\
Rotor configuration & $3 \mathrm{blades,} \mathrm{upwind}$ \\
Rotor diameter & $126 \mathrm{~m}$ \\
Hub height & $90 \mathrm{~m}$ \\
Rotor mass & $110,000 \mathrm{~kg}$ \\
Nacelle mass & $240,000 \mathrm{~kg}$ \\
Tower mass & $347,460 \mathrm{~kg}$ \\
Coordinate of overall CM & $(-0.2 \mathrm{~m}, 0.0 \mathrm{~m}, 64.0 \mathrm{~m})$ \\
\hline
\end{tabular}

The first step of the study is to find the steady state operating point of the system, around which it will oscillate due to periodic wave loads. Then, hydrodynamic wave loads on the platform are calculated with Aquaplus. Aquaplus is a linear frequency domain diffraction/radiation code developed at Laboratoire de Mécanique des Fluides from Ecole Centrale Nantes [5]. This codes calculates for each wave frequency $\omega$, the radiation force in terms of added mass $\mu(\omega)$ and wave damping $\lambda(\omega)$, and the wave induced exciting force $F_{\text {ex }}(\omega, \beta)$ (including diffraction loads) [6]. This calculation is done considering the platform at the operating point found with the static analysis.

Mooring loads on the system are modelled with a mooring stiffness matrix $K_{\mathrm{a}}$. Hydrostatic forces are taken into account with a hydrostatic stiffness matrix $K_{\mathrm{h}}$

FAST, an aero-elastic simulation code for wind turbine developed at NREL, has the ability to linearize a model about an operating point [7]. The model is linearized about the steady state operating point found in the static analysis. The model built in FAST takes into account the hydrodynamic radiation forces calculated with Aquaplus, mooring loads and hydrostatic forces.

FAST outputs the resulting mass, damping and stiffness matrices $M_{\text {res, }} L_{\text {res, }}, K_{\text {res }}$ resulting of the whole system: platform, wind turbine, mooring system. Finally, motion equation of the system under periodic wave loads in frequency domain with complex notation is:

$\left(-\omega^{2} M_{\mathrm{res}}(\omega)+i \omega L_{\mathrm{res}}(\omega)+K_{\mathrm{res}}(\omega)\right) \Delta q=F_{\mathrm{ex}}$

with $M_{\mathrm{res}}, L_{\mathrm{res}}, K_{\mathrm{res}}$ depending on incident wave frequency $\omega . \Delta q$ is the vector of system displacement around steady state position. The different components from the resulting matrices $M_{\text {res, }} L_{\text {res }}, K_{\text {res }}$

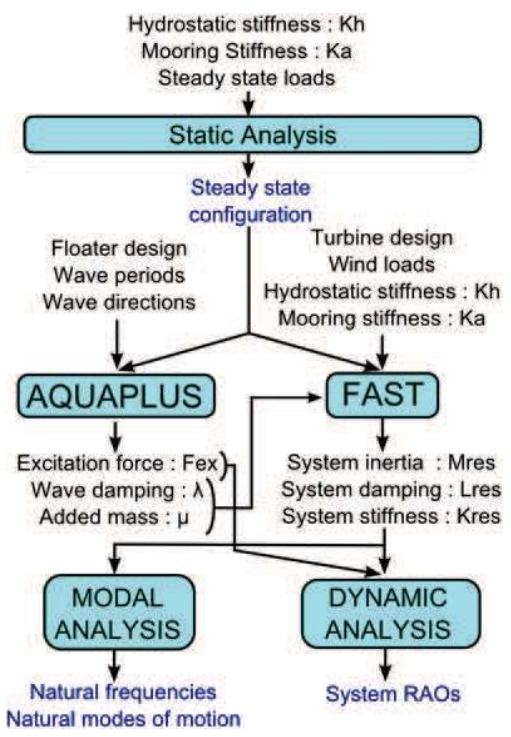

Fig. 2. Overall study approach. 
are detailed in [3]. Resolution of Eq. (2) for a 1-m incident wave gives access to system motion RAOs under wave loads.

The second part of this study is a modal analysis. It consists in the calculation of natural frequencies and modes, and modal damping coefficients of the whole system: platform, turbine, mooring, by resolving Eq. (2), for free motion (without forcing term $\left.F_{\text {ex }}\right)$. This calculation is based on the methodology for damped rotating system presented in Ref. [8]. but phases between motions are different. Modal damping coefficient of mode 4 is negative valued, sign of a possible loss of stability [8]. Modes 4 and 6 are represented respectively on Figs. 3 and 4. These modes show a very important coupling between roll and yaw motion. This coupling is not at the same phase in the two motions. Consequently, the system oscillates inversely in the two modes. These two modes are at the same frequency and will cancel one another.

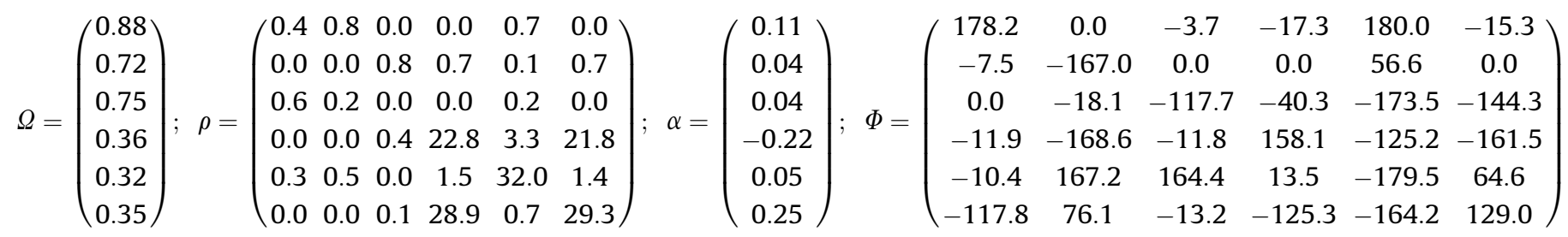

\section{Results}

\subsection{Steady state results}

Steady state pitch position of the system has been calculated by resolving Eq. (3). $K_{\mathrm{h}}$ is the hydrostatic stiffness matrix, $K_{\mathrm{a}}$ is the mooring stiffness matrix, $F_{\text {aeros }}$ is the steady state aerodynamic force on the turbine and $X_{\mathrm{S}}$ is the steady state position vector of the system 6 DOFs. Steady state pitch is $9.6^{\circ}$, and steady state roll is $0.5^{\circ}$. The floating wind turbine will oscillate around this position.

$\left(K_{\mathrm{h}}+K_{\mathrm{a}}\right) X_{\mathrm{s}}=F_{\text {aero }_{\mathrm{s}}}$

\subsection{Natural frequencies and modes of motion}

Results of the modal analysis are given in Eq. (4). Vector $\Omega$ contains the natural frequencies $\left.(\operatorname{rad~s})^{-1}\right)$ of the floating wind turbine. We call mode $1-6$ the natural modes associated with the 1-6 natural frequencies in the order they appear in vector $\Omega$. Columns of matrix $\rho$ represent these natural modes $1-6$. Vector $\alpha$ represents the modal damping coefficients associated with modes $1-6$, and matrix $\varphi$ represents the phases associated with the natural modes of motions.

The six natural frequencies of this system are located in the range of values that are excited by ocean wave spectrum. The first mode of motion at $0.9 \mathrm{rad} \mathrm{s}^{-1}$ is dominated by heave and is coupled with pitch and surge. The second mode at $0.7 \mathrm{rad} \mathrm{s}^{-1}$ is similar with the same coupled motion but is dominated by surge. These two modes show a coupling between the surge, pitch and heave motion of the system. This coupling between horizontal motions was attended. The third mode at $0.8 \mathrm{rad} \mathrm{s}^{-1}$ is dominated by sway, and shows an important coupling with roll and a smaller with yaw. This coupling between rotational motions was also attended. Natural frequencies 1, 2 and 3 are close, corresponding mode may be excited together. The fifth mode is dominated by pitch, and shows a small coupling with the other five DOFs. Coupling with translation surge, sway, heave is negligible, but the pitch-roll coupling is observable with a value of $10 \%$, and was not expected. Modal damping coefficients of these modes $1,2,3$ and 5 are positive, these natural modes are damped.

Natural frequencies 4 and 5 are at the same value of $0.4 \mathrm{rad} \mathrm{s}^{-1}$. The corresponding modal amplitude $\rho$ are approximately the same,

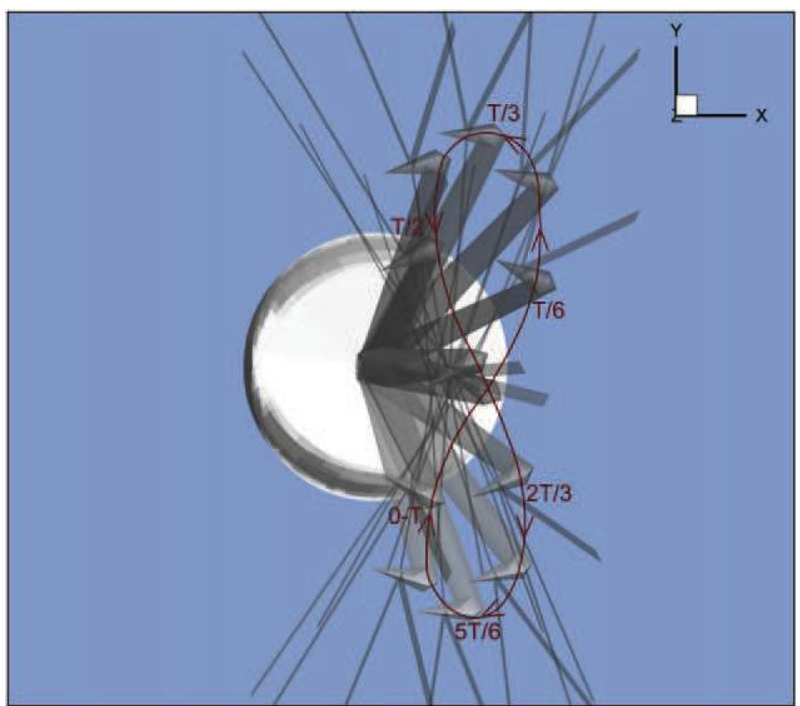

Fig. 3. Representation of natural mode 4 .

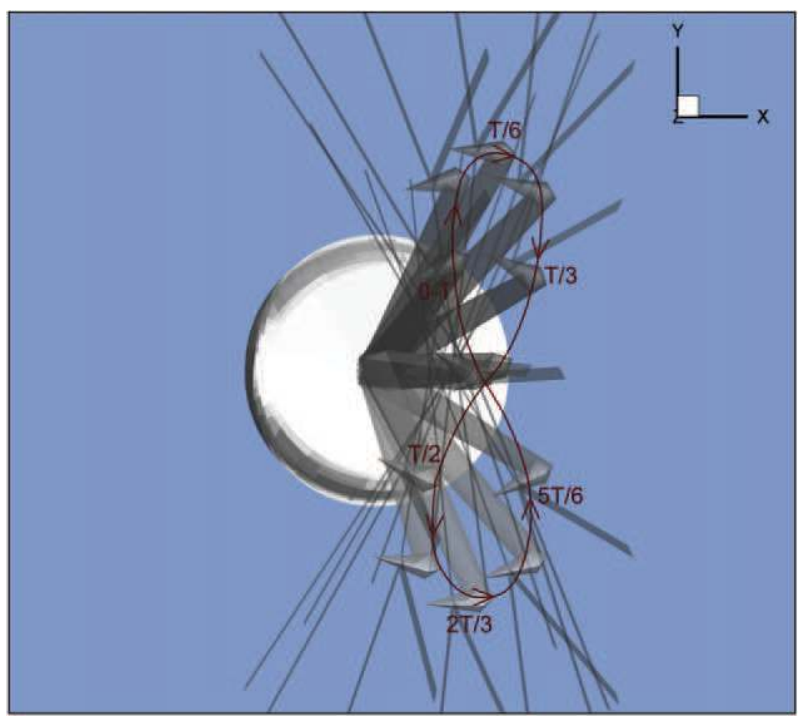

Fig. 4. Representation of natural mode 6 . 


\subsection{System RAOs regarding wave direction}

Response amplitude operators of the system, platform, mooring, and turbine are plotted in Fig. 5. These RAOs are calculated for five wave directions from $0^{\circ}$ to $180^{\circ}$. Direction $0^{\circ}$ represents a wave coming from negative $x$ direction. RAOs represent the responses of the system motions regarding wave frequency and direction.

Surge RAO, represented on Fig. 5(a), shows a large peak around $0.7 \mathrm{rad} \mathrm{s}^{-1}$ for all wave directions. When wave is aligned with $x$ axis, mode 2 , dominated by surge, is excited, this explains the important

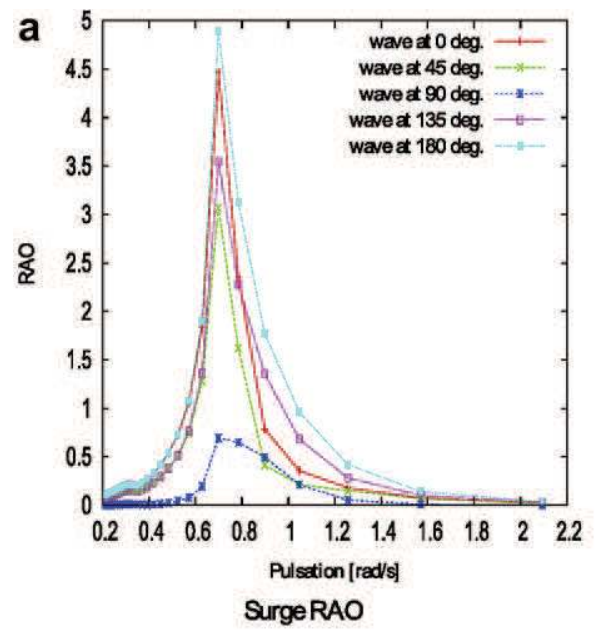

C

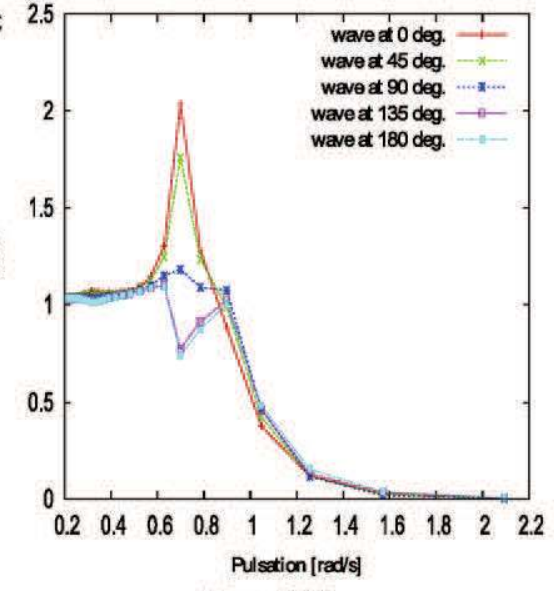

Heave RAO

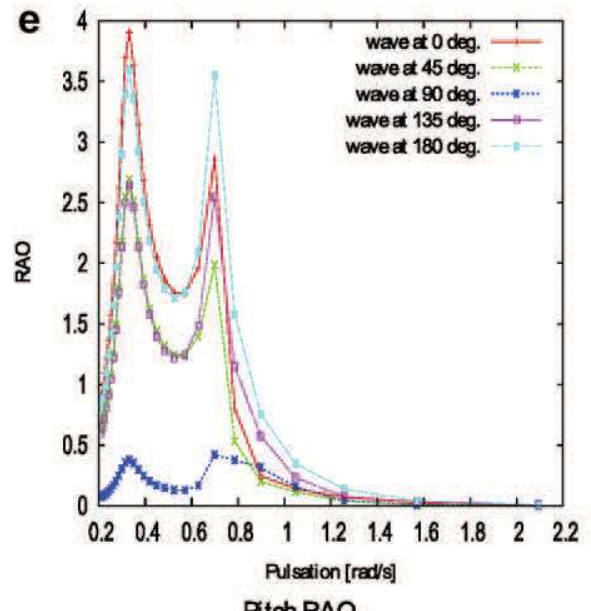

response for these wave directions. For wave coming from $90^{\circ}$, surge motion is not zero. Due to the steady state position, the floater is asymmetric, so the surge wave excitation/diffraction force is non-zero for $90^{\circ}$ wave direction. Furthermore, for a $90^{\circ}$ at $0.7 \mathrm{rad} \mathrm{s}^{-1}$ wave, heave component of modes 1 and 2 can be excited, and the system moves in surge due to the coupling between surge and heave for these modes.

Fig. 5(b) shows the sway response of the structure. Similarly to the surge response, it shows an important peak around $0.8 \mathrm{rad} \mathrm{s}^{-1}$. But for $0^{\circ}$ and $180^{\circ}$ wave direction there is quite no sway response
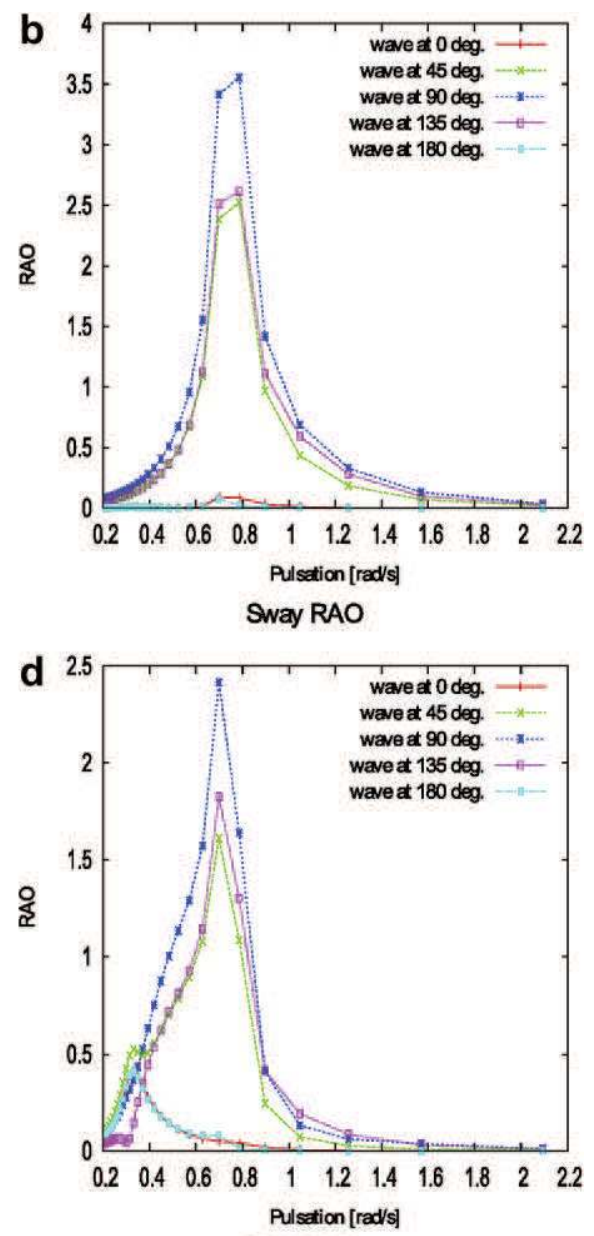

Roll RAO

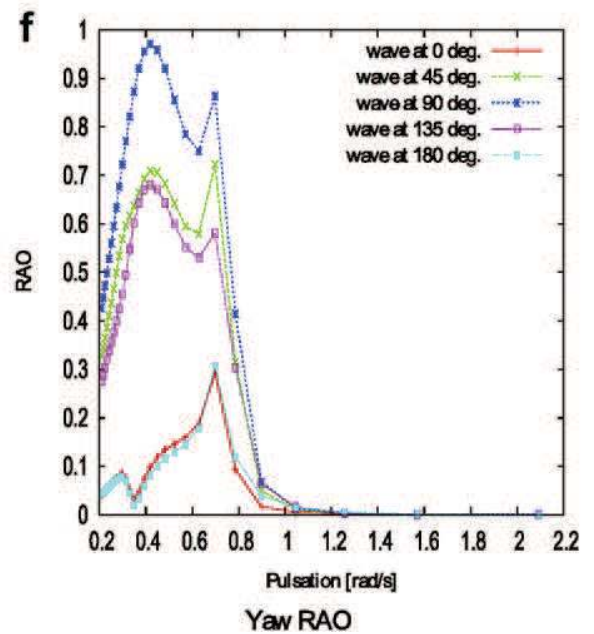

Fig. 5. System RAOs regarding wave direction. 
of the system. The important response at $0.8 \mathrm{rad} \mathrm{s}^{-1}$ when wave is in sway direction corresponds to excitation of mode 2 , dominated by sway. Contrary to surge response, there is no sway-pitch coupling to display sway motion when wave comes at $0^{\circ}$ or $180^{\circ}$, furthermore, sway wave excitation force is negligible for these direction.

Fig 5(c) represents the heave RAOs of the system. For a $0^{\circ}$ wave direction, the heave response is maximal at $0.7 \mathrm{rad} \mathrm{s}^{-1}$. For a $180^{\circ}$ wave direction the heave response at $0.7 \mathrm{rad} \mathrm{s}^{-1}$ shows a local minimum. This difference is not due to the heave wave excitation force, which is not very dependent of wave direction. For a $0.7 \mathrm{rad} \mathrm{s}^{-1}$ wave, mode 1 and 2 can display motion in heave. Mode 2 , dominated by surge, will be more excited for $0^{\circ}$ and $180^{\circ}$ wave. The excitation in phase of mode 1 and mode 2 for a wave at $0^{\circ}$, and excitation in opposite phase for a wave at $180^{\circ}$ may explain the respective maximum and minimum of response for these directions.

Roll response is represented on Fig. 5(d). It shows a large peak around $0.7 \mathrm{rad} \mathrm{s}^{-1}$ for wave directions of $45^{\circ}, 90^{\circ}$, and $180^{\circ}$. This peak is explained with the excitation of mode 3 sway-roll-yaw. It is remarkable that modes 4 and 6 don't show important response around $0.4 \mathrm{rad} \mathrm{s}^{-1}$. They should display important roll motion but as seen on Section 3.1, they are not in phase and cancel each other, and display only little roll motion non observable with a peak. For wave direction of $0^{\circ}$ and $180^{\circ}$, the curves show a small peak around $0.3 \mathrm{rad} \mathrm{s}^{-1}$. It corresponds to excitation of mode 5 , dominated by pitch with a small roll component.

Pitch RAOs are represented on Fig. 5(e). Motions are represented around the steady state position, which is $9.6^{\circ}$ in pitch. The first one around $0.3 \mathrm{rad} \mathrm{s}^{-1}$ comes from excitation of mode 5 dominated by pitch. The second around $0.7 \mathrm{rad} \mathrm{s}^{-1}$ comes from excitation of modes 1 and mode 2 which contain a pitch component. When waves come from $90^{\circ}$, pitch motion is small, and not easy to explain. It may come from excitation of roll-pitch coupling in mode 4 and 6. Motion amplitudes are small because these modes cancel one with each other.

Finally Fig. 5(f) shows the yaw response of the system. Amplitude of response of the system is small for every wave direction and for every wave frequency. As there is no excitation in yaw, the motion in yaw comes from the coupling with other DOFs. There is yaw coupling in the natural modes 3, 4, 5 and 6. Strong coupling between roll and yaw in modes 4 and 6 may explain the more important motion when wave direction crosses wind.

\section{Conclusions}

This study highlights importance of modal analysis to better understand the behaviour of floating wind turbine. It brings out natural frequencies around which system motions are important, and natural modes which help to understand the coupling between the system DOFs. Effect of wave direction relative to wind has been studied for a particular floating wind turbine system. It appears that natural modes are excited differently regarding wave direction. The case where wind and wave are not aligned brings out maximal yaw response. In this study the wind turbine is modelled with damping and stiffness matrices. Others have developed time domain simulation tools which give access to model with more DOFs for the wind turbine [9]. It should be interesting to study the effect of wave direction relative to wind in time domain to look at the transient events. Furthermore, to be able to predict correctly the behaviour of floating wind turbine system, it will be necessary to study the effect of non linear hydrodynamic on the coupling between system motions.

\section{Acknowledgements}

The authors would like to acknowledge ADEME (the French environment agency) and Région Pays de la Loire for funding the Phd program in which this study has been done.

\section{References}

[1] Wayman EN. Coupled dynamics and economic analysis of floating wind turbines systems. Master thesis, Massachusetts Institute of Technology; 2006.

[2] Wayman EN, Sclavounos PD, Butterfield S, Jonkman J, Musial W. Coupled dynamic modelling of floating wind turbine systems. In: Offshore technology conference, 1-4 May 2006, Houston, TX; 2006.

[3] Philippe M, Babarit A, Ferrand P. Effect of wave direction relative to wind on the motions of offshore floating wind turbine systems. In: International conference and exhibition on ocean energy 2010, Bilbao, Espagne; 2010.

[4] Jonkman J, Butterfield S, Musial W, Scott G. Definition of a 5-MW reference wind turbine for offshore system development. NREL/TP-500-39060. Golden, CO: NREL; 2009.

[5] Delhommeau G. Seakeeking codes AQUADYN and AQUAPLUS. In: 19th WEGEMT SCHOOL numerical simulation of hydrodynamics: ships and offshores structures; 1993.

[6] Molin B. Hydrodynamique des Structures Offshore. Editions TECHNIP; 2002.

[7] Jonkman JM, Buhl ML. FAST user guide. Golden, CO: National Renewable Energy Laboratory; 2005.

[8] Gmür T. Dynamique des structures: analyse modale numérique. Lausanne: Presses polytechniques et universitaires romandes; 1997.

[9] Jonkman J. Dynamics modelling and load analysis of an offshore floating wind turbine. Ph.D. thesis, Department of Aerospace Engineering Sciences, University of Colorado; 2007. 